\title{
International Journal of Arabic Language Teaching
}

P-ISSN: 2684-690X E-ISSN: 2686-214X

https://l-journal.metrouniv.ac.id/index.php/IJALT

Tậtbìq al-Adawāt an-Nạ̣wiyyah li an-Nạtiqīn bi Ghairi al-'Arabiyah min Khilāli alKitāb Bulugh al-Marām li Ibnu Hejajar al-'Asqalāni

\section{Wendy Morrizha Pritantoro}

Khartoum International Institute for Arabic Language

\section{Article History:}

Received : April 152020

Revised : May 19, 2020

Accepted : May 28, 2020

Published : June 1, 2020

\section{Keywords:}

Accurate meaning, Aims of the words, important.

\section{*Correspondence Address:}

wendymorrizha@gmail.com

\begin{abstract}
This paper is descriptive and analytical. This research aims to provide an application for teaching grammatical tools to non-Arabic speaking students through the texts of the book Bulugh al-Maram. As for the research problem, it is a lot of students of Arabic who speak other than others, who find it difficult to know the meanings of grammatical tools, their sections, their locations, their rulings and their uses. This research aims to teach grammatical tools for speakers of other Arabic language through the hadits of the Prophet, may God's prayers and peace be upon him, in the book "Bulugh al-Maram by Ibn Hajar Al-Asqalani" and using it in teaching others who speak other than Arabic and his study ability to understand Arabic texts. This paper results that understanding the purposes of Arab speech, according to its different types, and the purposes of the methods of religious texts are based on knowledge of the meanings of grammatical tools, and that they represent an important aspect of the Arabic language, because they have accurate meanings and abundance of uses.
\end{abstract}




\section{أ أ. المقدمة}

تُعَدُ اللغة العربية بتراثها الأدبي والعلمي والثقافي الضخم إحدى لغات العالم العظيمة، وقد اكتسبت هذه الصفة منذ ظهور الإسلام ونزول القرآن بها، ومنذ ذلك التاريخ اقترنت اللغة العربية بالإسلام، واكتسبت صفة القداسة لدى المسلمين في جميع أنحاء العالم.

وقد تلقى سلفنا الصالح من الصحابة والتابعين هذه اللغة، وتلك الخصيصة الكبرى للغة العربية بالتبجيل والإكبار والدعوة إليها، حيث قال أمير المؤمنين عمر بن الخطاب رضي الله عنه: تعلَّمُوا العربية، فإنها تُثبّت العقل وتزيد في المروءة، وعرف النحاة للأدوات النحوية أهميتها في دراسة النحو العربي، وحظيت دراسة الأدوات والحروف بنصيب كبير في ثنايا كتب النحو². فالأدوات النحوية كما وردت في بعض كتب التراث العرابي، تؤدي وظائف نحوية، ومعاني دلالية، وهي تضم حروفا وغيرها مما شاكلها في الوظيفية والدلالة. وجاءت دراسة الأدوات في كتب النحو العامة وفي الكتب التي تناولت حروف المعاني على نحو نظري تعتمد على بعض الشواهد القليلة، وإذا كان معنى الأداة لا يتضح إلا بوظيفتها السياقية، فإن دراسة هذه الأدوات في نص متكامل لا بد أن تعطي نتائجها التطبيقية التي قد تتفق وتلك الأقوال النظرية وقد تختلف معها33. إذن فقد عرف النحاة للأدوات النحوية أهميتها في دراسة النحو العربي، وأخذت دراسة الأدوات حظا كبيرا من كتب النحو العامة. هذا بحث لدرس الأدوات النحوية للناطقين بغيرها من خلال أحاديث النبي صلى الله عليه وسلم في كتاب بلوغ المرام لابن حجر العسقلاني وتوظيفها في التعليم للناطقين بغيرها اللغة العربية وتمكنه الدراسية من فهم 1أبو بكر أحمد بن الحسين البيهقي، الجامع لشعب الإيمان، تحقيق: د. عبد العبي عبد الحميد حامد، مكتبة الرشد، ج3، ط1أ، الرياض 1423هـ - 2003م، ص 210

20مطفى شيخ مصطفى، معاني الحروف، دلالات الأدوات النحوية ومعانيها في القرآن الكريم دراسة وتوظيفا، (بيروت : مؤسسة

$$
\text { الرسالة ناشرون) 1439هـ - } 2018 \text { مـ، ص. } 7
$$

3خمد أحمد خضير، الأدوات النحوية ودلالاتما في القرأن الكريم، (القاهرة : مكتبة الأنجلو المصرية) 2018 من هـ، ص. 3 
النصوص العربية. لذلك أهتم الباحث باستحلاء هذه النصوص وتوضيح الأدوات الواردة فيها. مؤلف الكتاب الإمام العلامة الحافظ أبو الفضل أحمد بن علي بن محمد بن حجر العسقلاني - وعسقلان بفتح العين، وسكون السين، وتخفيف اللام، مدينة من أعماق فلسطين قريب غزة - المصري الشافعي؛، وقيل : هو أحمد بن علي بن محمد بن محمد بن علي بن محمود بن أحمد بن أحمد بن العسقلاني المصري الشافعي، فريد الوقت، مفخرة الزمان، بغية الحافظ، علم الأئمة الأعلم، عمدة المققين، خاتمة الحافظ المبرزين، وقضاء المشهورين أبو الفضل شهاب الدين 5. ولد مصر في اليوم الثاني عشر من شعبان عام ثلاثة وسبعين وسبمائة (12/ شعبان / 773 هـ).6 وقيل : / 23

تأتي أهمية البحث مما يلي: توصيته معاني الأدوات النحوية وأقسامها ومواقعها واستعمالاتما من خلال النصوص الشريفة في كتاب بلوغ المرام. ثم تطبيق الأدوات النحوية للدارسين الناطقين بغير العربية من خلال نصوص كتاب بلوغ المرام. ب. منهج البحث

يتبع الباحث في هذا البحث المنهج الوصفي التحليلي. وأما حدود البحث فهي حدود موضوعية تتمثل في الأدوات النحوية التي وردت في نصوص كتاب الجامع من خلال كتاب بلوغ المرام.

4 عبد الله بن عبد الرمن البسام، توضيح الأحكام من بلوغ المرام، (مكتبة الأسد : مكة المكرمة)، 1323 هـ/ 2003 مـ ط 5،

ج، 1 ، ص. 19

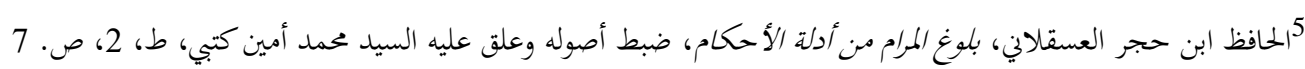

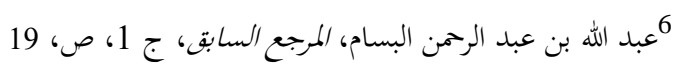




\section{د.البحث}

\section{أ. تعريف الأدوات النحوية}

الأدوات هي جمع من الأداة وهي الآلة والوسيلة، وفي الإصطلاح هي الكلمة التي تربط بين أجزاء الكلام، وتكون دلالتها في غيرها كأل التعريف وسين الإستقبال، وهي الحرف الذي يقابل الاسم والفعل في التقسيم الثلاثي للكلمة في النحو العربي، قال سيبويه : "الكلم : اسم وفعل وحرف جاء لمعنى، ليس باسم ولا فعل.7 وقيل أيضا الأداة هي التي يستخدمها المتكلم لإحكام دلالة الجملة، وإتمام إفادتما حتى يطابق الكلام مقتضي الحال، وللربط بين الأسماء والأفعال والجمل من أجل إنشاء الأسلوب، ومن ثم تكتسب الأداة معناها من السياق. 8 ذلك أن الأدوات تتضمن أصناف الحروف، كما هي عند النحاة، وما شاكلها من الأسماء والأفعال. فهي ما يتوسل به المتكلم لإنشاء معان مختلفة يقتضيها المقام، وظروف التعبير، كما أن من شأن هذه الأدوات، في بعض الأحيان، جلب الحركة أو قطعها (السكون) لما يقع بعدها من كلمات. جاء مصطلح الأداة عند سيبويه مساويا لمصطلح الحرف، في قوله : (وللقسم والمقسم به أدوات في حروف الجر، وأكثرها الواو، ثم الباء)؛، حيث جعل الواو والباء من حروف الجر. وجاء عنده أيضا بمعنى الآلة التي تستخدم في العمل سواء أكانت فعلا أم حرفا. 10 الأدوات النحوية أو حروف المعاني مصطلحات أطلقها النحاة على تلك الكلمات التي لا تحمل دلالة مستقلة في ذاقا، بل تكتسب دلالنها من السياق اللغوي.

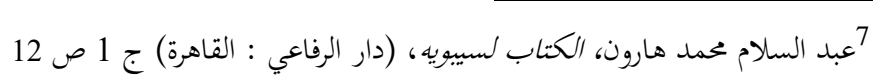

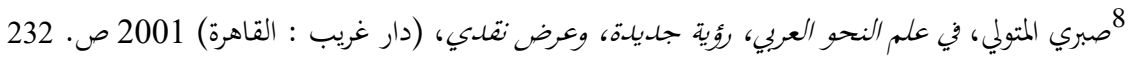

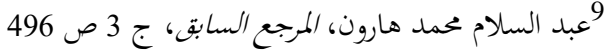

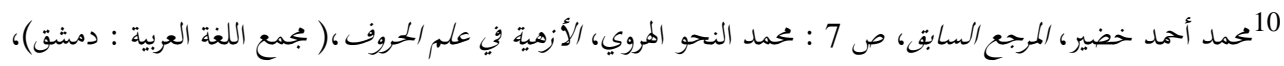

$$
\begin{aligned}
& \text { 1993م، ص } 26
\end{aligned}
$$


هذا الاتساع الذي بدأه الفراء وتبعه فيه المبرد ذلك، نجده أيضا عند ابن هشام فيما أطلق عليه مصطلح (المفردات) وقال أنه يعني بما الحروف، وما تضمَّن معناها من الأسماء والظروف، 11 وهو ما جاء عند السيوطى صراحة حيث قال : (وأعني بالأدوات الحروف وما شاكلها من الأسماء والأفعال والظروف)، 12 وبذلك يتسع مفهوم

$$
\text { بالأداة عندهم ليشمل الحروف وما يشبهها من أسماء وأفعال وظروف. }
$$

إن معرفة لسان العرب واجبة، إذ به يتوصل إلى فهم مقاصد الشرع وأحكامه، فلا يفهم كلام الله المنزل ولا يهتدى إلى تحصيل معنى حديث رسول الله صلى الله عليه وسلم إلا بفهم كلام العرب مفردات وتركيبا، وملا

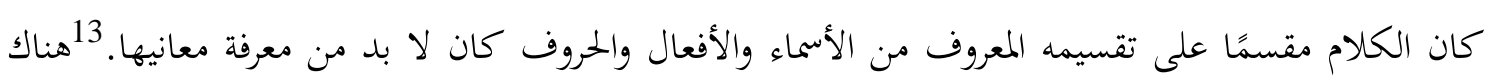

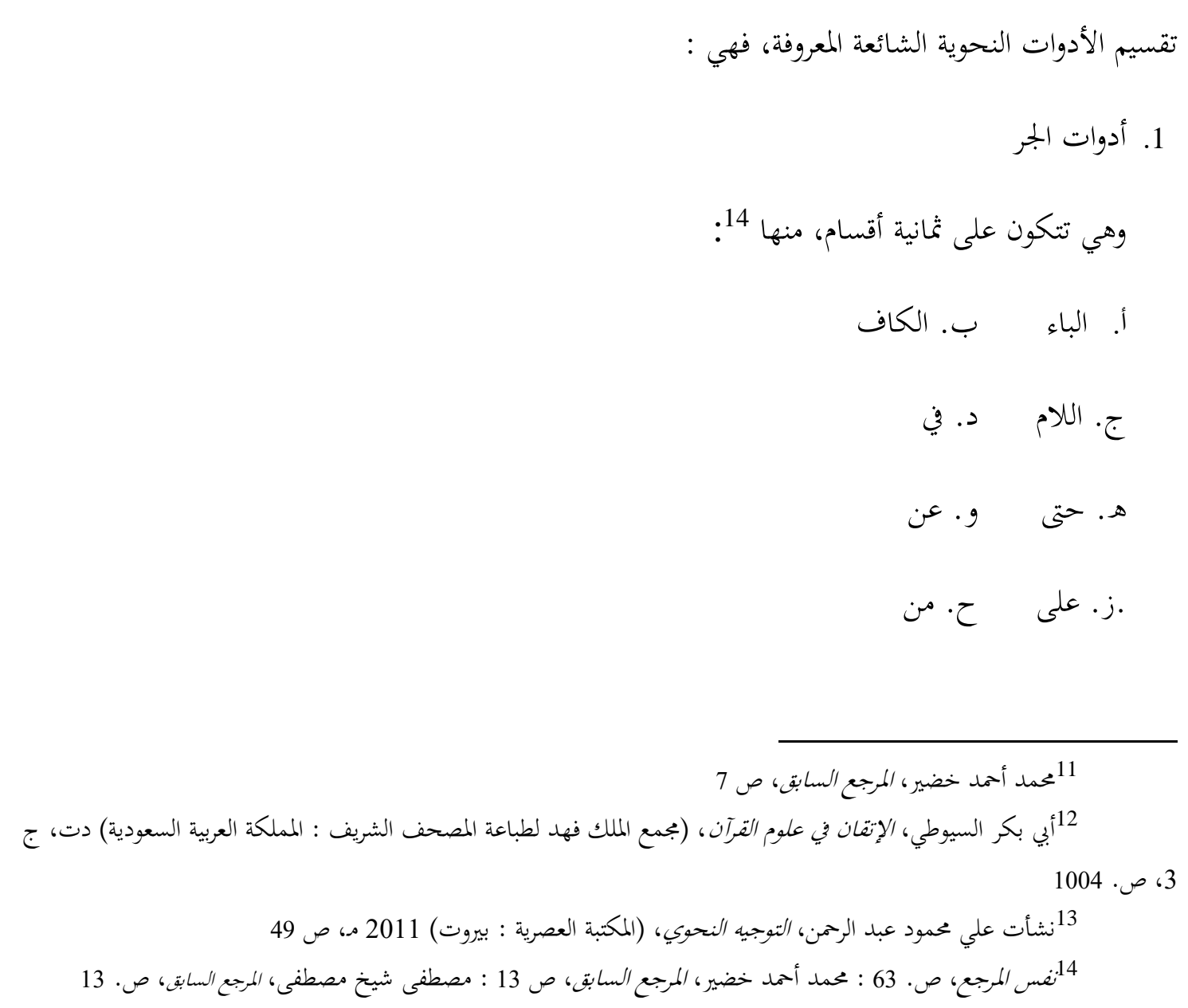




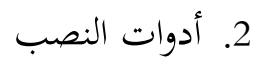

وهي تتكون على ثلاثة أقسام، منها 15:

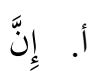

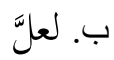

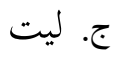

3. أدوات الجزم

وهي تتكون على ثلاثة أقسام، منها 16:

أ.

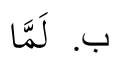

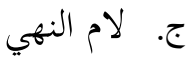

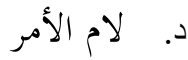

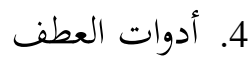

وهي تتكون على أربعة أقسام، منها 17:

أ. الفاء

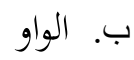

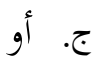

د.

15 نشأت علي محمود عبد الرمن، المرجع السابق، ص. 53

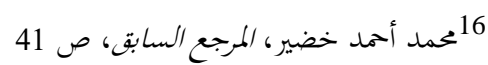

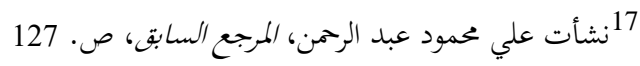




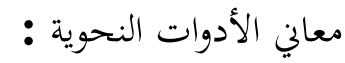

$$
\begin{aligned}
& \text { أما معاني الأدوات النحوية الشائعة المعروفة، فهي : }
\end{aligned}
$$

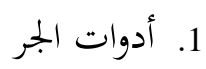

$$
\begin{aligned}
& \text { وقد حدَّد النحاة معاني أدوات الجر فيما يلي : }
\end{aligned}
$$

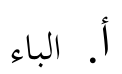

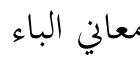

$$
\begin{aligned}
& \text { تأتي الباء للدلالة على المعاني التالية 18: } \\
& \text { 1-الاستعانة : }
\end{aligned}
$$

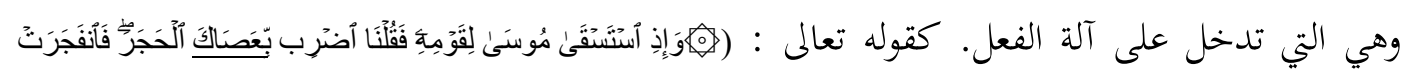

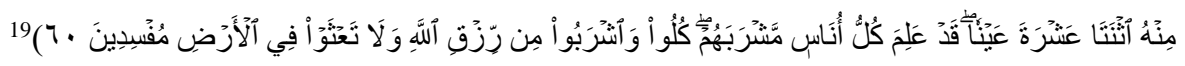
2-

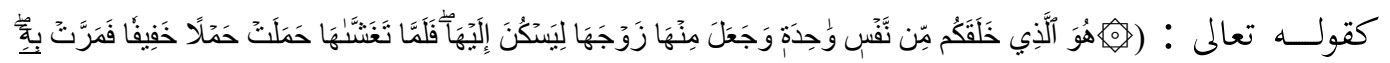

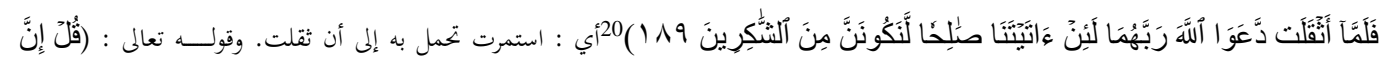

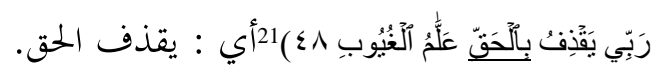

وتكون الباء للتعدية، وبواسطتها يعتدى الفعل اللازم إلى المفعول به، وتقوم مقام الهمزة، نحو قولــــ

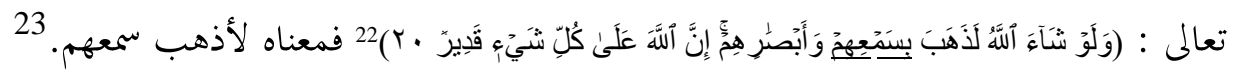

18 10صطفى شيخ مصطفى، المرجع السابق، ص 35 : ممدد علي سلطاني، الأدوات النحوية ومعانيها في القرآن الكريم، (در

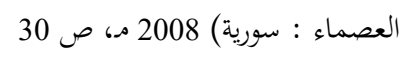

$$
\begin{aligned}
& 19 \text { سورة البقرة : } 60 \\
& \text { 20 سورة الأعراف : } 189 \\
& \text { 21 سورة سبأ : } 48
\end{aligned}
$$




$$
\text { 3- }
$$

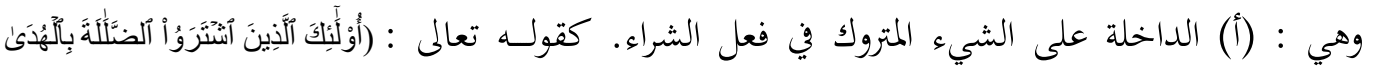

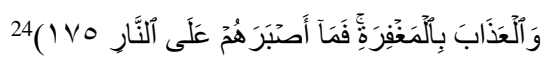

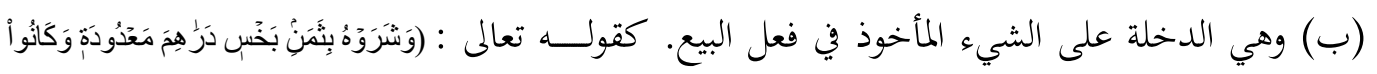

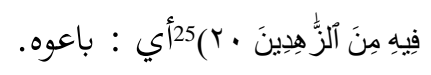

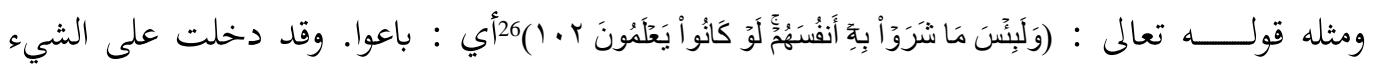
المأخوذ.

$$
\text { 4- المصاحبة بمعنى (مع) }
$$

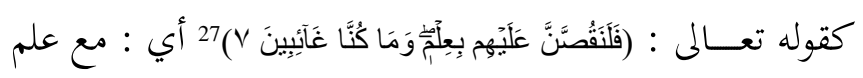$$
\text { ب. ب. ب الكاف }
$$

$$
\text { الكاف ولها معان متعددة منها } 28
$$

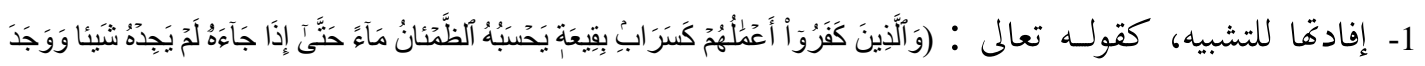

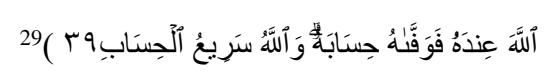

\footnotetext{
20 : 22$$
23
$$$$
175 \text { : } 24
$$$$
20 \text { : } 25
$$$$
102 \text { : } 102
$$$$
7 \text { : } 72
$$$$
\text { 28 }
$$$$
284 \text { 2011 }
$$$$
39 \text { : } 29
$$ 


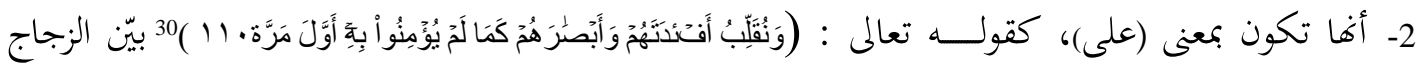
ما حمله القوم على أن الكاف في قوله (كما) بمعنى (على)، وآخرون على أنه بمعنى (من أجل) أي من أجل ما لم يؤمنوا به أول مرة. وذكر أبو حيان موافتتها إلى (على) إلا أنسه لم يذكر أحكامهــــ في تفسيره

$$
\text { 3- فيل أحال معرفة الأحكام إلى كتب النحو. }
$$

أشار أبو حيان إلى أنه يحدث فيها معنى التعليل ونسبه الزركشي والسيوطي إلى الأخفش. وأكد الزجاج

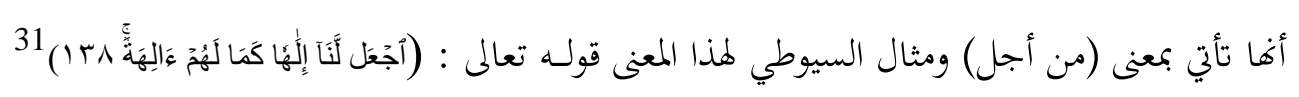

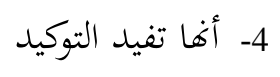

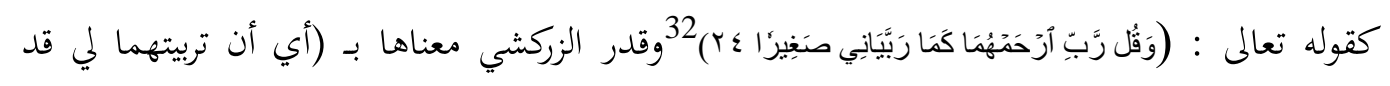
وجدت كذلك أوجد رحمتك لمما يارب). 33 ج. اللام ولما معان متعددة منهاب34

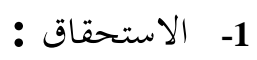

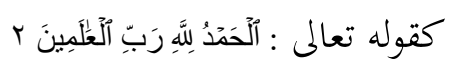

$$
\begin{aligned}
& \text { 2- }
\end{aligned}
$$

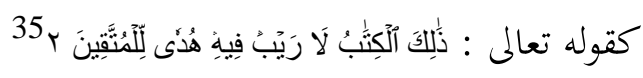

$$
\begin{aligned}
& 110 \text { : } 110 \\
& 138 \text { : } 110 \\
& \text { 32 } 24 \text { : } 24 \\
& 33 \\
& \text { 34 3صطفى شيخ مصطفى، المرجع السابق، ص } 61 \text { : : محمد علي سلطاني، المرجع السابق، ص } 13
\end{aligned}
$$




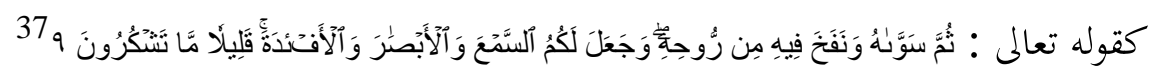

(إلى -

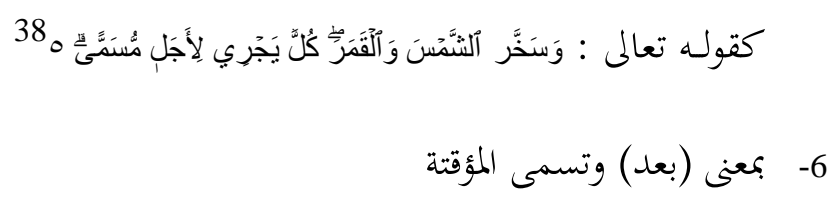

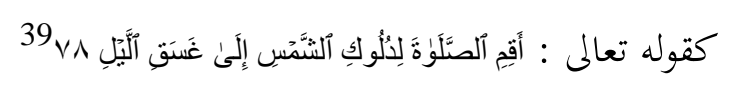

$$
\text { وتَرِدُ للدلالة على المعاني التالية }
$$

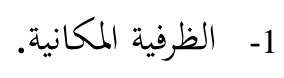

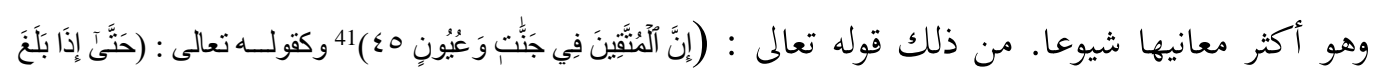

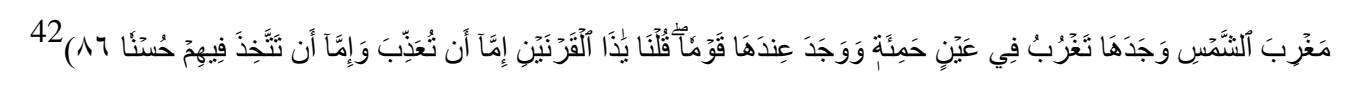

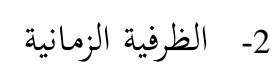

$$
\begin{aligned}
& 2 \text { 25 } 35 \\
& 284 \text { : } 284 \\
& 9 \text { : } 37 \\
& 58 \\
& 78 \text { : } 39 \\
& \text { 40مصطفى شيخ مصطفى، المرجع السابق، ص } 29 \text { : محمد علي سلطاني، المرجع السابق، ص. } 39 \\
& 45 \text { : } 41 \\
& 86 \text { : } 42
\end{aligned}
$$




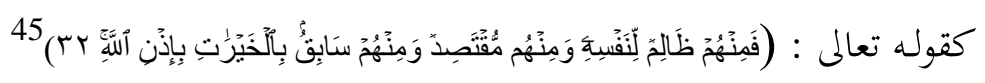

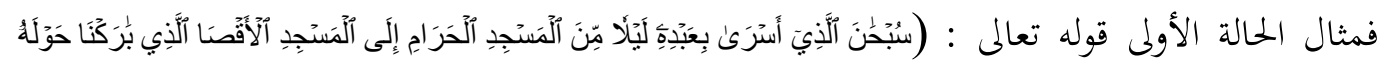

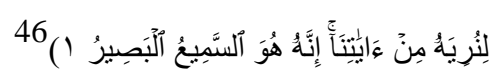
يقول سيبويه رحمه الله تعالى في هذا : وأما (من) فتكون لابتداء الغاية في الأماكن، وذلك قولك : من مكان كذا وكذا إلى مكان كذا وكذا. وتقول إذا كتبت كتابا : من فلان إلى فلان. فهذه - الأسماء سوى الأماكن - بمنزلتها.

$$
\begin{aligned}
& 43 \\
& 44 \text { 4صطفى شيخ مصطفى، المرجع السابق، ص } 46 \text { : } 46 \text { : محمد علي سلطاني، المرجع السابق، ص } 24 \\
& 32 \text { : } 35 \\
& \text { } 16 \\
& \text { } 25 \text { سورة نوح : }
\end{aligned}
$$




$$
\begin{aligned}
& \text { معاني إلى } \\
& \text { 1- انتهاء الغاية المكانية }
\end{aligned}
$$

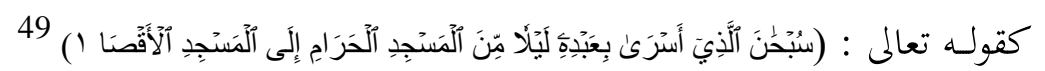

$$
\begin{aligned}
& \text { 2- 2 - 2 انتهاء الغاية الزمنية }
\end{aligned}
$$

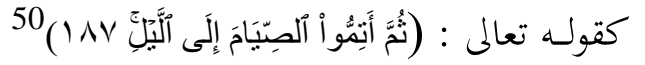

$$
\begin{aligned}
& \text { ز ز ز مَتَّى } \\
& \text { معاني حتى. } \\
& \text { ترد (حتى) للدلالة على المعاني التالية 51. }
\end{aligned}
$$

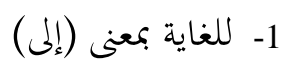

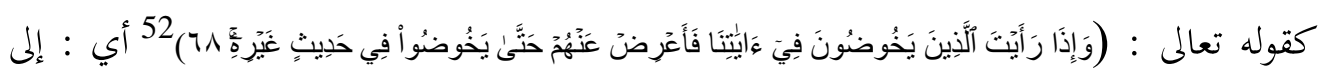

$$
\text { أن يخوضوا. }
$$

$$
\text { 2- 2 - لتعليل بمعنى (كي) }
$$

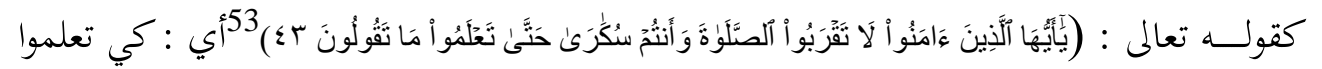

3- إستثناء بمعنى (إلا)

$$
\begin{aligned}
& 48 \text { 4صطفى شيخ مصطفى، المرجع السابق، ص } 55 \text { : محمد علي سلطاني، المرجع السابق، ص } 19 \\
& \text { } 19 \\
& 187 \text { : } 180 \\
& \text { 515 مصطفى شيخ مصطفى، المرجع السابق، ص } 24 \text { : : محمد علي سلطاني، المرجع السابق، ص } 46 \\
& 68 \text { : } 52 \\
& 43 \text { : } 53
\end{aligned}
$$




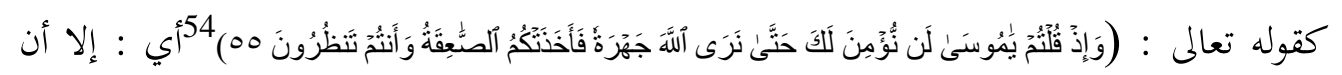

$$
\text { نرى الله جهرةً }
$$$$
\text { ح. عَنْ }
$$$$
\text { لها معان }
$$$$
\text { 1- المجاوزة والبعد }
$$$$
\text { وهذا أصلها، نحو : سرتُ عن البلدِ }
$$

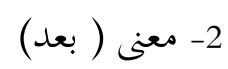$$
\text { نحو : عن قريب أزورك }
$$

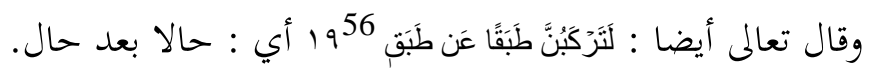$$
\text { 3- معنى (على) }
$$

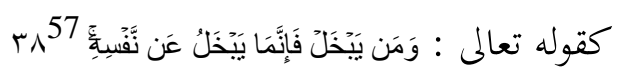

$$
\text { 4- التعليل }
$$

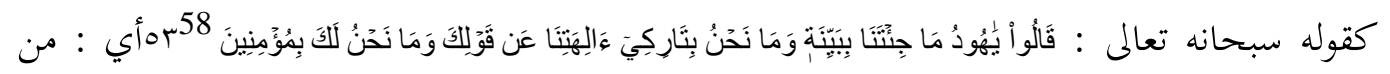

$$
\begin{aligned}
& \text { أجل قولك. }
\end{aligned}
$$

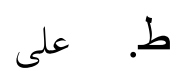

$$
\begin{aligned}
& \text { معاني على 59. - - 5 } \\
& 55 \text { : } 54 \\
& \text { 55 5صطفى الغلابيني، جامع الدروس العربية، (المكتبة التوفقية : القاهرة) } 2014 \text { م، ص. } 495 \\
& 19 \text { : } 56 \\
& 38 \text { : } 57 \\
& 53 \text { : } 58
\end{aligned}
$$




$$
\begin{aligned}
& \text { أ. (على) الحرفية : وترد للدلالة على المعاني التالية : } \\
& \text { - }
\end{aligned}
$$

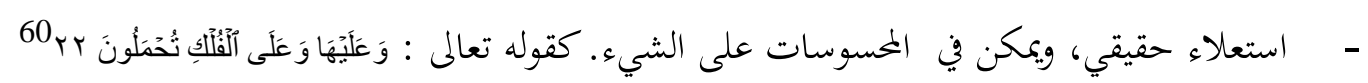

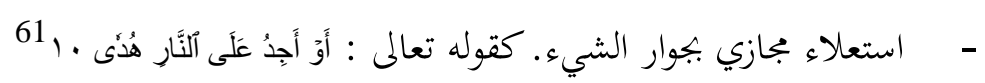

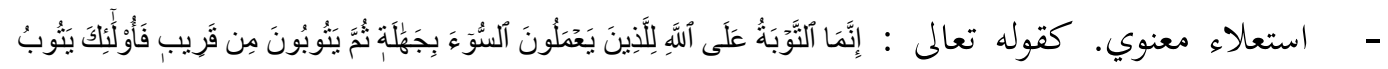

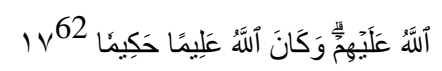

فقوله : (يتوب الله عليهم) على : للاستعلاء المعنوي. وقوله : (إنما التوبة على الله...) (على)

$$
\text { بعنى : من }
$$

$$
\text { 2- 2 - لمصاحبة بمعنى (مع) }
$$

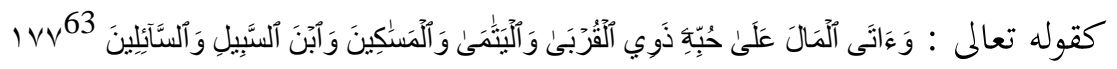

$$
\text { 3- لمجاوزة بمعنى (عن) }
$$

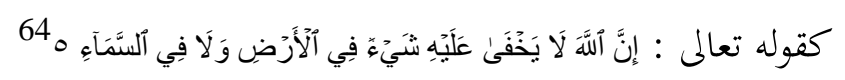

$$
\text { 4 - للتعليل }
$$

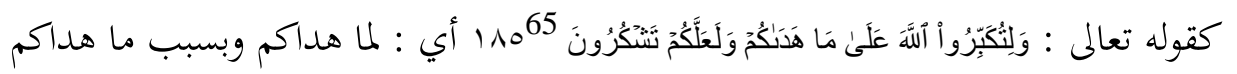

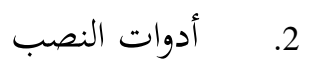

$$
\begin{aligned}
& \text { 59 مصطفى شيخ مصطفى، المرجع السابق، ص } 13 \text { : محمد علي سلطاني، المرجع السابق، ص } 50 \\
& 22 \text { : } 60 \\
& 10 \text { : } 10 \text { سورة طورة المونون : } 62 \\
& 17 \text { : } 62 \\
& 177 \text { : } 173 \\
& 64 \\
& 185 \text { : } 185
\end{aligned}
$$




$$
\text { وقد أِ إنَّ مدَّد النحاة معاني أدوات النصب الشائع فيما يلي : }
$$

وهذه الكلمة بكسر الهمزة وتشديد النون مفتوحة، حرف مشبه بالفعل، والكلمة هذه مختصة بالدخول على

$$
\text { الجملة الاسمية، وتستعمل إنَّ لمعان أهمها 66. }
$$

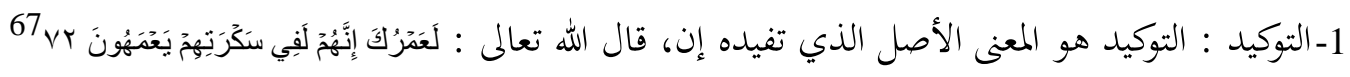

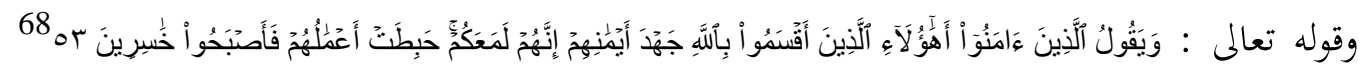

$$
\text { فقد أفادت التوكيد ونفي الشك والإنكار. }
$$

2- الربط : تستعمل إِنَّ ربط الكلام، وسقوطها ليس مستحبا وإذا سقطت كان الكلام مختلا. وقوله تعالى :

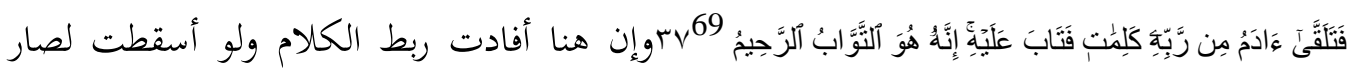

$$
\text { الكالام نابيا، فضلا عن التوكيد. }
$$

1- التوقُع :ترجي المحبوب، والإشفاق من المكروه، ويكون ذلك في المكان، نخو : لعل الحبيب قادم.

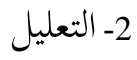

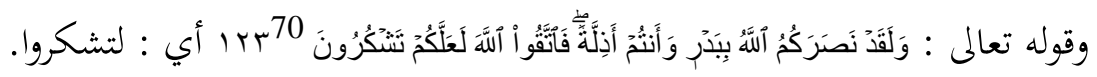

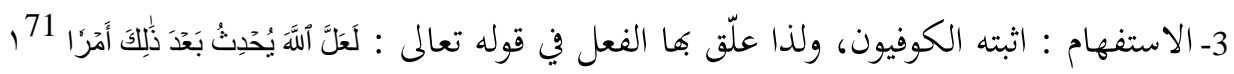

$$
\begin{aligned}
& 66 \text { خضر أبو العينين، المرجع السابق، ص } 88
\end{aligned}
$$

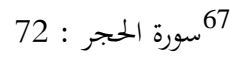

$$
\begin{aligned}
& 53 \text { : } 68 \text { سورة المائدة المجر : } 67 \\
& 69 \text { سورة البقرة : } 37 \\
& 123 \text { سورة آل عمران : } 123
\end{aligned}
$$




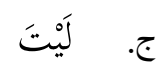

$$
\begin{aligned}
& \text { أما عمل ليت، منها :تنصب الإسم وترفع الخبر. } \\
& \text { معنى ليت } \\
& \text { (لَيْتَ) حرف للتمني، يطلب به مالا يمكن وقوعه لأحد سببين: }
\end{aligned}
$$

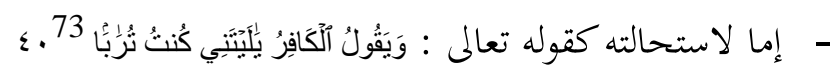

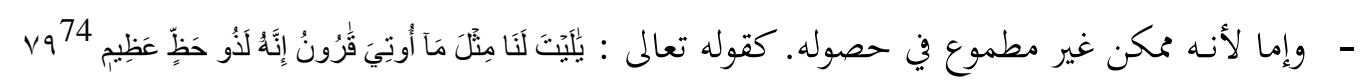

$$
\text { فلا تكن في الجواب، فلا يقال : (ليت غدا يجيء) }
$$

وعن الشمني قوله : يجب ألا يكون للتمني توقع وطماعية في وقوعه، وإلا صار تَرَبِيًا.

$$
\text { 3. أدوات الجزم }
$$

$$
\text { وقد حلَّد النحاة معاني أدوات الجزم فيما يلي : }
$$

حرف نفي يفيد معنى السلب، والجزم يجزم الفعل المضارع بعده، وقلب يقلب معنى المضارع من الحاضر إلى

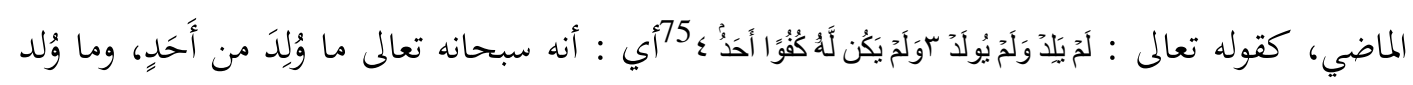

$$
\text { منه أحدٌ. }
$$

$$
\begin{aligned}
& 1 \text { : } 11 \text { سورة الطلاق } \\
& \text { 72 7صطفى شيخ مصطفى، المرجع السابق، ص } 157 \\
& \text { } 730 \text { سورة النباء } \\
& 79 \text { : } 74 \text { : } 73 \text { : } 73 \text { القصوة النصص: : } \\
& \text { 75 سورة الإخلاص : } 34
\end{aligned}
$$


تتألف (لَمَّا) من كلمتين، هما : (لم) و (ما) مع احتفاظ كل منها معنها قبل التركيب. فلملم) لنفي ما مضي، و(ما) لنفي ما قرب من الحاضر، فاجتمع في (لَمَّا) معنيان، هما 76.

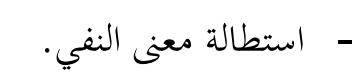

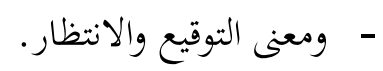
وقال حسن بهارون في كتابه، أما معاني لمها فهي 77 1- اللظرفية الزمنية، نحو : لما جئت إليه قام من مجلسه 2- لنفي الماضي نفيا مستمرا إلى الحال، نحو : لما يحضرِ الأستاذُ.

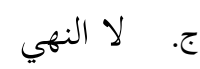

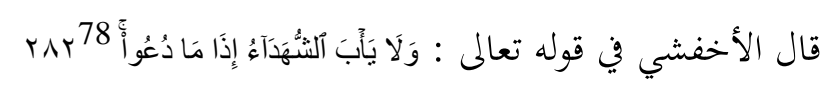
(جزم لأنه غي)، وهي إشارة إلى معنى النهي في (لا) هو الذي يجعل الفعل مجزوما.79

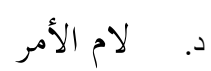

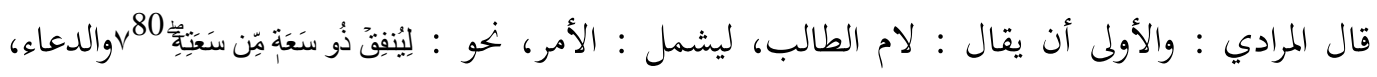

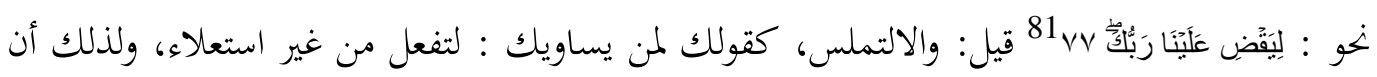
الطلب إذا ورد من الأعلى فهو أمر، وإذا ورد من الأدنى فهو دعاء، وإذا ورد من المساوى فهو التماس.82

$$
\text { 76 } 70
$$

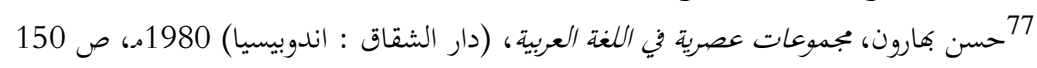
282 : 78

$$
\begin{aligned}
& \text { 79 7ممد أحمد خضير، المرجع السابق، ص } 41 \\
& 80 \\
& 81 \\
& \text { 82 8ممد أحمد خضير، المرجع السابق، ص } 47
\end{aligned}
$$




$$
\begin{aligned}
& \text { 4. أدوات الربط } \\
& \text { وقد حلَّد النحاة معاني أدوات الربط فيما يلي : }
\end{aligned}
$$

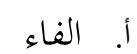

$$
\begin{aligned}
& \text { أما معاني الفاء فهي } 83 \\
& \text { 1- للترتيب، نحو : أُطْلْبِ الْعِلْمَ فَاعْمَلَهُ } \\
& \text { 2- للسببية، نحو : لا تكسل فتندم } \\
& \text { 3- للزيادة، نخو : أخذت هذا فقط } \\
& \text { 4- لارتباط الجواب، نحو : من عمل صالحا فلنفسه }
\end{aligned}
$$

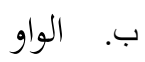

$$
\begin{aligned}
& \text { وأما معاني الواو فكما يلي 84: } \\
& \text { 1- للقسم، نحو : و الله ما فعلتُ هذا } \\
& \text { 2- للعطف، نهو : ذهب علي وصالح إلى السوق } \\
& \text { 3- للحال، نحو : لاتنم والشمس طالعة } \\
& \text { 4- للمعية، نهو : لاتنه عن خلق و تأتي مثله } \\
& \text { ج. } \\
& \text { جاءت (أو ) بمعان مختلفة، وأما معاني أو فبما يلي } 85 \text { : } \\
& \text { 1- للتخيير، نهو : خذ هذا أو ذاك } \\
& 83 \text { حسن بهارون، المرجع السابق، ص } 124 \text { : خضر أبو العينين، المرجع السابق، ص. } 260
\end{aligned}
$$

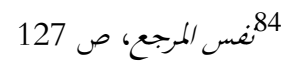

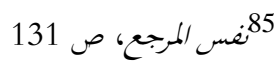




$$
\begin{aligned}
& \text { 2- للشك، نحو : نسيت أنى وضعته في الخزانة أو في الدرج } \\
& \text { 3- للغاية، نحو : اجتهد في الدرس أو تنجح }
\end{aligned}
$$

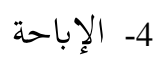

والفرق بين التخيير، والإباحة جواز الجمع في الإباحة ومنعه في التخيير، ومن أمثلة ذلك قوله تعالى :

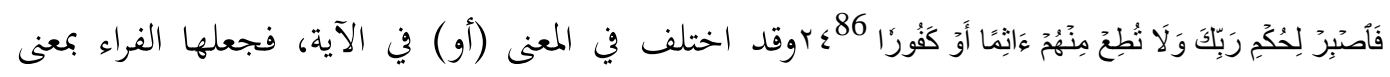
(ولا)، إلا أنه قال بعد ذلك إن معناها هنا قريب من معنى الواو، ومثّل بقولم : لأعطينك سألت أو سكتَّ، قال معناه : لأعطينك على كل حال.

أورد ابن مالك (تم) في حروف العطف حيث قال :فـالعطف مطلقا : بواو، ثم، فـا حتى، أم، أو، كـ (فيك صدق ووفا) ${ }^{87}$ وأما ثم فهو حرف عطف يفيد الترتيب مع التراخي أي وجود مسافة زمنية بين المعطوف والمعطوف عليه. 88 وجعل ابن مالك ثم في حروف العطف التي تشرك المعطوف مع المعطوف

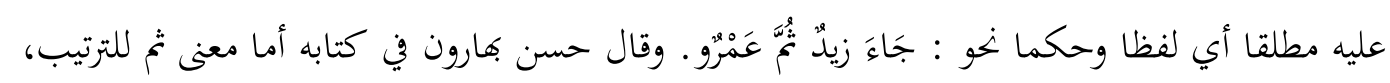
نو :دخل الشيوخ تخم الشُبُّنَانُ

\section{ج. التطبيق الأدوات النحوية في كتاب بلوغ المرام :}

وهذا من إحدى لإعداد الدروس النموذجية في تعليم الأدوات النحوية من خلال كتاب بلوغ المرام فكما

88

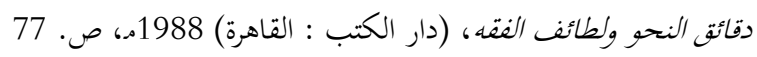




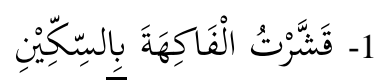
-2

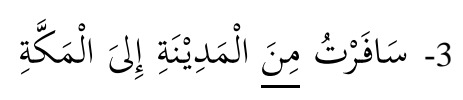
4- بَبِ اجْعَلْنِ مِنَ الصَّالحِيْنَ 5- الجَائزَّة لِلسَّابقِقِ

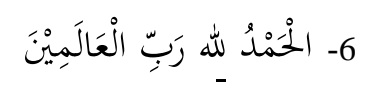
الكلمات في جميع الأمثلة السابقة تتكون من أدوات الجر، منها الباء ووِنْ ولام. ففي الطائفة الأولى تجدها مسبوقة ب-(الباء)، الباء في المثالين (1 و 2) تفيد لإستعانة وهي تدخل على آلة الفعل. وإذا تأملنا في المثال الأول أنَّ الفاكهة قُسِرَتْ بالسكين، وفي المثال الثاني قد كتبت بالآلة وهي القلم. ففي الطائفة الثانية بحدها مسبوقا بـ(من)، "من" في الرقم (3) يفيد لابتداء المكانية وهي من مكان إلى مكان آخر. أي من مكان كذا وكذا إلى مكان كذا وكذا. و"من" في الرقم (4) يفيد البعضية وهي جزء من كلي. أي رب اجعلني بعض الصالحين. ففي الطائفة الثالثة تجدها مسبوقا بـ(لام)، "لام" في الرقم (5) يفيد للملك وهو صاحب الأمر أو صاحب الشيء. وإذا تأملنا في المثال (5) أن الجائزة للسابق أو للمتقدم. و "لام" في الرقم (6) يفيد الاستحقاق وهو أهلية وجدارة للمكافأة أو الاحترام. وإذا تأملنا في المثال (6) أن الحمد لله رب العالمين، لا الحمد إلا لله عز 
أما أدوات الجر منها الباء ومن واللام، وهي تجر الاسم إذا سبقه أداة من أدوات الجر الآتية. ولأدوات الجر معان ووظائف. أما الباء لها معان متنوعة منها الاستعانة وكذلك (من) لها معان كثيرة منها لابتداء المكانية والبعضية وكذلك اللام لما معان مختلفة منها الملك والاستحقاق. دراسة تطبيقية من الحديث النبوي عن أدب الأكل والشرب :

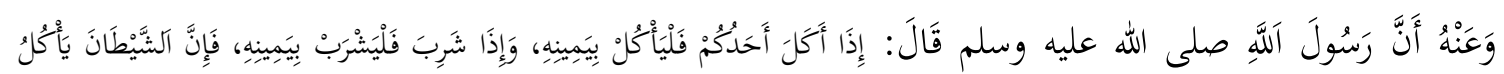

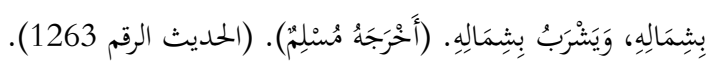

في هذا الحديث يبين عن أدب الأكل والشرب، أمر رسول الله صلى الله عليه وسلم أن الأكل بيمينه، الباء في قوله (بيمينه) تفيد الاستعانة وهي تدخل على آلة الفعل. اليد هنا تستخدم للأكل والشرب. وحث رسول الله صلى الله عليه وسلم لأمته إذا أَكَلَ أَحَدُكُمْ فَلْيَأْكُلْ بِيَمِينِه، وَإِذَا شَرِبَ فَلْيَشْرَبْ بِيَمِينِهِ، وهذا من سنته ولنا من أمته لابد أن يعمله. وفى رسول الله صلى الله عليه وسلم للأكل والشرب بشماله، لأن الشيطان يأكل ويشرب بشماله لا بيمينه.

أما الأدوات النحوية في هذا الحديث فهي الباء وهي أداة من أدوات الجر. والباء لها معان منها الاستعانة. الاستعانة هي وسيلة على الفعل أو تدخل على آلة الفعل. : تَمَرْينَاتُ إملاء الفراغات الآتية بكلمات مناسبة من النص!

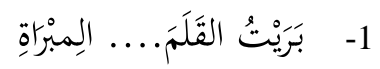

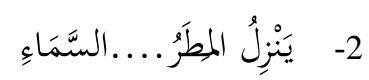
3- الحَنَعَ الحَدَّادُ نَعْلاًا....الحِصَانِ 


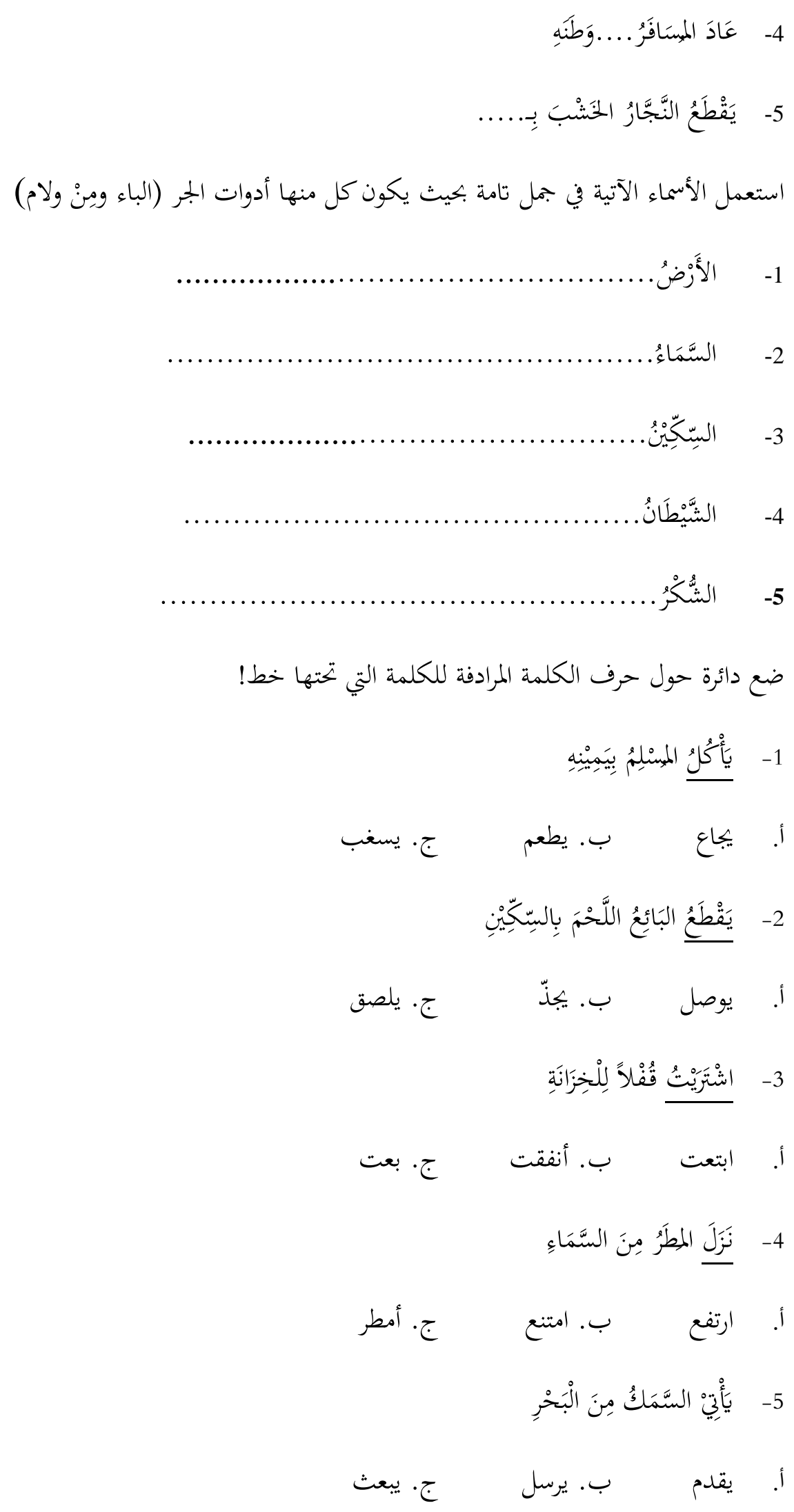


ضع أمام كل كلمة في القائمة الأولى ضدّها الذي تختار من القائمة الثانية!

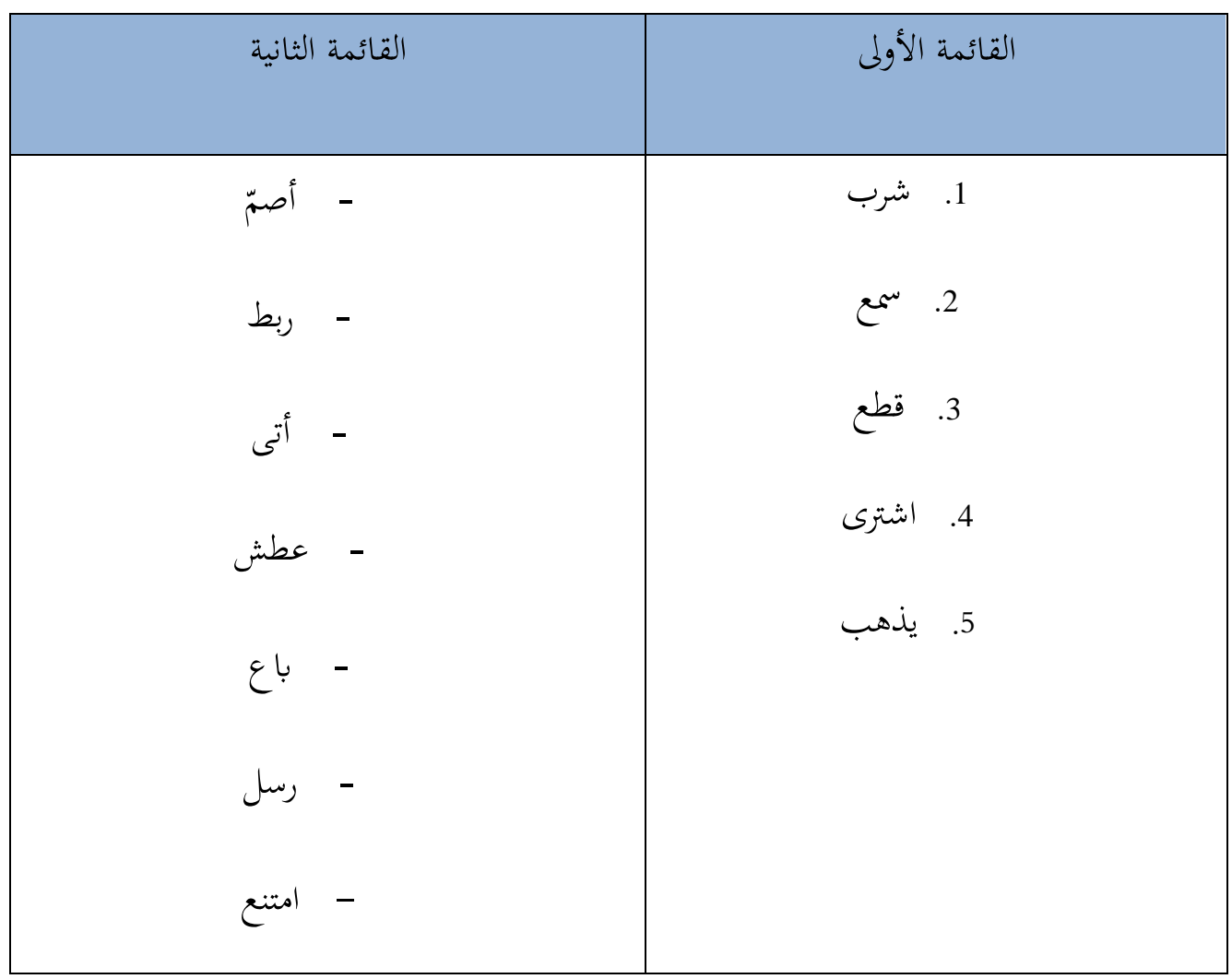

د. داتمة

ومن خلال التحليل، وصل الباحث إلى النتائج المهمة في هذا البحث وهي :إن فهم مقاصد كلام العرب،

على اختلاف صنوفه، ومقاصد أساليب النصوص الدينية مبني أكثرها على معرفة معاني الأدوات النحوية، وأها

تمثل جانبا مهما من جوانب اللغة العربية، لما لها دقة المعاني، وغزارة الاستعمال لحفاظ على لغة العربية في القرآن الكريم والحديث النبوي الشريف. 
يوصي الباحث على متعلمي اللغة العربية الاهتمام وإعطاء العناية لتعليم الأدوات النحوية لما لها من أهمية قصوى في دلالات، وتوجيه لمعان ومقاصد النصوص الدينية ومرادها. أن تقوم بتعليم الأدوات النحوية التي تتضمن الأمثلة السهلة الواضحة حتى يتوضح معنى الأدوات النحوية وتظهر دلالتها وتستبين وظيفتها.

المصادر والمراجع : : المصادر

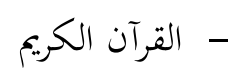

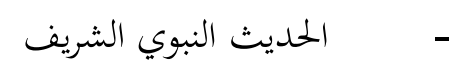

المراجع

- أبو بكر أحمد بن الحسين البيهقي، الجامع لشعب الإيمان، تحقيق: د. عبد العبي عبد الحميد حامد، مكتبة

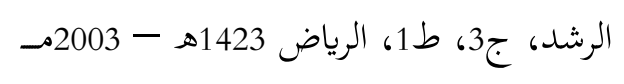

- أبي بكر السيوطي، الإتقان في علوم القرآن، (مجمع الملك فهد لطباعة المصحف الشريف : المملكة العربية

$$
\text { السعودية) دت، ج } 3 .
$$

- الحافظ ابن حجر العسقلاني، بلوغ المرام من أدلة الأحكام، ضبط أصوله وعلق عليه السيد محمد أمين كتبي،

- حسن بهارون، مجموعات عصرية في اللغة العربية، (دار الشقاق : اندوبيسيا) 1980مـ

- - خضر أبو العينين، معجم الحروف العربية، (دار أسامة للنشر والتوزيع : عمان) 2011مـ

- مبري المتولي، في علم النحو العربي، رؤية جديدة، وعرض نتحي، (دار غريب : القاهرة) 2001 مـ

- عبد السلام محمد هارون، الكتاب لسيبويه، (دار الرفاعي : القاهرة) ج 1 ص 12 
- عبد الله بن عبد الرحمن البسام، توضيح الأحكام من بلوغ المرام، (مكتبة الأسد : مكة المكرمة)، 1323 هـ/ . 1003 - - عيسى الرماني النحوي، معاني الحروف، (المكتبة العصرية : بيروت) 2014 مـ - محمد أحمد خضير، الأدوات النحوية ودلالاتما في القرأن الكحيم، (القاهرة : مكتبة الأنجلو المصرية) 2001 مـ - محمد النحو الهروي، الأزهية في علم الحروف،( مجمع اللغة العربية : دمشق)، 1993هـ - محمد علي سلطاني، الأدوات النحوية ومعانيها في القرآن الكريم، (در العصماء : سورية) 2008 مـ - محمود سعد، حروف المعاني بين دقائق النحو ولطائف الفقه، (دار الكتب : القاهرة) 1988هـ - مصطفى شيخ مصطفى، معاني الحروف، دلالات الأدوات النحوية ومعانيها في القرآن الكريم دراسة وتوظيفا، (بيروت : مؤسسة الرسالة ناشرون) 1439هـ - 2018 مـ - نشأت علي محمود عبد الرحمن، التوجيه النحوي، (المكتبة العصرية : بيروت) 2011 مـ 